\title{
Assessment of the Knowledge of Poultry Farmers and Live Poultry Sellers to Preventive and Control Measures on Bird Flu, Benin City, Nigeria
}

\author{
V. Y. Adam, ${ }^{1}$ A. M. Qasim, ${ }^{1,2}$ and M. O. Kazeem ${ }^{3}$ \\ ${ }^{1}$ Department of Community Health, University of Benin, Benin City, Nigeria \\ ${ }^{2}$ National Veterinary Research Institute, Livestock Investigation Department, Poultry Division, Vom, Nigeria \\ ${ }^{3}$ Department of Microbiology, University of Ilorin, Ilorin, Nigeria
}

Correspondence should be addressed to A. M. Qasim; abdullahifirm@yahoo.com

Received 21 July 2013; Revised 29 October 2013; Accepted 31 October 2013; Published 19 January 2014

Academic Editor: M. L. Wilson

Copyright ( 2014 V. Y. Adam et al. This is an open access article distributed under the Creative Commons Attribution License, which permits unrestricted use, distribution, and reproduction in any medium, provided the original work is properly cited.

\begin{abstract}
Investigated was the knowledge of preventive measures of avian influenza from farmers, live chicken sellers, and poultry veterinarian in Benin City, Edo State, Nigeria. A cross-sectional descriptive study using standardized questionnaire was conducted. Respondents included 236 poultry farmers, live chicken sellers (LCS), and veterinarian aged 12-70 years in contact with birds through husbandry. The study duration was from October 2010 to May 2011. Participants knowledge on transmission sources showed low understanding with highest being from bird-bird (57.3\%). The medium most commonly utilized was electronic media $(82.5 \%)$ as information source. Respondents thought that vaccination of birds (80.6\%) would prevent infection. Farmers' education on bird flu needs to be improved through veterinary public health and health promotion approach. Nonpharmaceutical preventive measures such as hand washing freely and avoidance of eye, nose, and mouth touching must be improved.
\end{abstract}

\section{Introduction}

During an outbreak of avian influenza among poultry, there is a possible risk to people who have contact with infected birds or surfaces that have been contaminated with secretions or excretions from infected birds [1]. Avian influenza (AI) is a disease peculiar to avian species; it has been reported recently to have caused diseases in human through close contact with infected chicken [1]. The recent emergence of highly pathogenic avian influenza virus (HPAI) strains in poultry and their subsequent transmission to humans in Southeast Asia have raised concerns about the potential pandemic spread of lethal disease [2]. The small numbers of the human deaths associated with the highly pathogenic avian influenza virus (HPAIV) H5N1 appeared to be from direct exposure to infected birds on farms and in markets [2].

So far outbreaks have receded globally. Sporadic cases do occur in farms, signaling endemicity. Nigeria is surrounded by four countries with long porous borders with high risk of introduction of diseases of animal (zoonotic), fish, and plant during trade and movement [3]. Approximately 1.5 million birds have died or been depopulated as a result of avian influenza infection among poultry in Nigeria. In addition, one human fatal case was reported in the country [4]. There were four recorded outbreaks in Edo State from 2006 to 2008, three of which occurred in farms in Benin City. During this period the live poultry markets did not report cases of bird flu (Federal Livestock Department, Benin City, unpublished). This study was conducted to assess the knowledge of poultry farmers and live poultry sellers on the preventive measures against bird flu in Benin City, Nigeria.

\section{Materials and Method}

Benin City, the study area is southern Nigeria, is comprised of a population of 3,497,502 people based on the 2006 census [5]. Benin City has the largest concentration (>95\%) of poultry farms in Edo State. It remained a major transit route for poultry distribution to the South-South zone and parts of Southeast Zone, Nigeria from the hatcheries in Ibadan, Oyo 
state, Southwest Nigeria. Large numbers of day old chick broiler, cockerel, and pullets, turkey poult, and also points of lay (18-21 week old) pullets are transported on road to and through Benin City. Also indigenous chicken, Japanese quail, pigeons, guinea fowl, water birds, and other wild birds are transported from the northern Nigeria to and through Benin City [6]. Poultry eggs from commercial farms are transported from Benin City to the northern zones, Nigeria.

Farmers were identified by list of members of Poultry Association of Nigeria (PAN), Edo State. Out of the 91 listed members, 76 were members who located their farms in Benin City. These populations represent farmers with the low and high density flock sizes and were given questionnaire at their weekly poultry association meeting. Those farmers (163) who are not registered members of PAN were also reached through visitation to a total of 15 farms, 9 veterinary drug, and 5 feed stores and the live animal markets (LAM). Data were collected by self-administered questionnaire to the participants, who fill in and returned to designated Veterinary stores along Murtala Mohammad Way, Benin City.

The questionnaire was also administered to 48 live chicken sellers (LCS) who are mostly illiterate by interview at the five LAM, such as Oba market, Oliha market, Third circular junction market, Aduwawa market, and New Benin market. The questionnaire comprises questions on the demographic characteristics of participants and 46 questions on the knowledge of bird flu which included sources of information, transmission, and the practice of prevention and control measures at farms and markets. In this study, the disease was identified as "bird flu" because this was the term most commonly used in the media in Nigeria at the time of the 2006-2007 epidemic and was accepted by the public. The study period covered October 2010-May 2011. Research assistants (6 veterinary doctors and 7 animal health technologists) who are poultry veterinarian and assistants, respectively, were trained for 2 days. Verbal informed consent was obtained from the participants. Respondents' confidentiality was assured and that the research had no harm to the respondents. Analysis was conducted by using SPSS 15.0 statistical software to generate frequency distributions.

\section{Result}

In this study, 236 (77.9\%) respondents participated in the research and 39 respondents declined participation with reasons such as there is no need, no monetary benefit, and outright rejection. Twenty farmers did not return their questionnaire.

The 236 respondents involved in the research included $56.8 \%$ males and $43.2 \%$ females. The age groupings were $21-40$ years $(47.5 \%)$ as the highest, $41-60$ years $(41.5 \%), 0-$ 20 years $(5.9 \%)$, and $\geq 61$ years $(5.1 \%)$. More married people (69.1\%) were engaged than single (29.2\%) population in poultry farming. Most participants attended secondary and tertiary education (72.0\%) and primary (22.9\%) and 3.0\% had no formal education. The others occupational group owns more poultry farms $40.4 \%$; poultry farmers accounted for
TABLE 1: Awareness on information sources concerning bird flu by poultry farmers and live poultry sellers in Benin City.

\begin{tabular}{lccc}
\hline \multirow{2}{*}{ Information sources variable } & \multicolumn{3}{c}{ Frequency $(\%), n=234$} \\
& Yes & No & Total \\
\hline Heard about bird flu & $229(97.9)$ & $5(2.1)$ & $234(100.0)$ \\
Through television & $193(82.5)$ & $41(17.5)$ & $234(100.0)$ \\
Radio & $135(57.7)$ & $99(42.3)$ & $234(100.0)$ \\
Newspaper & $92(39.3)$ & $142(60.7)$ & $234(100.0)$ \\
Colleagues & $95(40.6)$ & $139(59.4)$ & $234(100.0)$ \\
Health worker & $47(20.1)$ & $187(79.9)$ & $234(100.0)$ \\
Place of worship & $10(4.3)$ & $224(95.7)$ & $234(100.0)$ \\
Seminar/workshop & $52(22.2)$ & $182(77.8)$ & $234(100.0)$ \\
Others & $9(3.8)$ & $225(96.2)$ & $234(100.0)$ \\
\hline
\end{tabular}

Multiple response, $n$ : number of respondents, \%: percentage, others: media such as internet and school.

TABLE 2: Awareness of the sources of transmission of bird flu by poultry farmers and live poultry sellers in Benin City.

\begin{tabular}{lccc}
\hline \multirow{2}{*}{ Variable } & \multicolumn{3}{c}{ Frequency $(\%), n=234$} \\
& Yes & No & Total \\
\hline Bird-bird & $134(57.3)$ & $100(42.7)$ & $234(100.0)$ \\
Bird-man & $118(50.4)$ & $116(49.6)$ & $234(100.0)$ \\
Man-bird & $22(9.4)$ & $112(90.6)$ & $234(100.0)$ \\
Man-man & $34(14.5)$ & $200(85.5)$ & $234(100.0)$ \\
Pig-man & $25(10.7)$ & $209(89.3)$ & $234(100.0)$ \\
Bird-pig & $32(13.7)$ & $202(86.3)$ & $234(100.0)$ \\
Bird feces & $71(30.3)$ & $163(69.7)$ & $234(100.0)$ \\
Handling of eggs & $62(26.5)$ & $172(73.5)$ & $234(100.0)$ \\
Vehicles & $40(17.1)$ & $194(82.9)$ & $234(100.0)$ \\
Slaughter surfaces & $68(29.1)$ & $166(70.9)$ & $234(100.0)$ \\
\hline
\end{tabular}

Multiple response, \%: percentage.

29.2\% and LPS are $23.3 \%$ while veterinarian $3.8 \%$ and pork sellers $0.8 \%$, respectively.

Information sources through which farmers heard about bird flu were radio (57.7\%), newspaper (39.3\%), colleagues (40.6\%), and seminar/workshop (22.2\%); the medium most commonly utilized was electronic media (82.5\%) (Table 1).

Farmers knowledge of sources of bird flu transmission revealed bird-bird 57.3\%, bird-man 50.4\%, man-bird 9.4\%, slaughter surfaces $29.1 \%$, bird feces $30.3 \%$, vehicles $17.1 \%$, and handling of eggs $26.5 \%$ (Table 2).

Respondents awareness of transmission through contacts showed low to high levels with $39.7 \%$ indicating that avian influenza can infect only chicken and $67.9 \%$ showing that bird flu can infect man. Transmission through contact with infected birds $73.9 \%$ and close contact with infected person $56.8 \%$ were revealed. Respondents $41.5 \%$ indicated that many birds died and $37.2 \%$ reported to veterinary authority. Visitation to farms showed $67.5 \%, 66.2 \%$, and $71.4 \%$ (Table 3 ).

Respondents (80.6\%) believed that vaccination of bird will prevent bird flu and $86.6 \%$ are aware that bird flu can be prevented; $86.2 \%$ cover their mouth when coughing and sneezing; fewer respondents $(23.7 \%)$ indicated using face mask while working in the pen and training of workers on 
TABLE 3: Awareness of bird flu transmission through contact and reporting to veterinary authority.

\begin{tabular}{lccc}
\hline \multirow{2}{*}{ Variable } & \multicolumn{3}{c}{ Frequency (\%), $n=234$} \\
& Yes & No & Total \\
\hline Bird flu infects only chicken & $93(39.7)$ & $141(60.3)$ & $234(100.0)$ \\
Bird flu can infect man & $159(67.9)$ & $75(32.1)$ & $234(100.0)$ \\
By touching infected chicken & $120(51.3)$ & $114(48.7)$ & $234(100.0)$ \\
Contact with infected birds & $173(73.9)$ & $61(26.1)$ & $234(100.0)$ \\
Close contact with infected & $133(56.8)$ & $101(43.2)$ & $234(100.0)$ \\
person & $97(41.5)$ & $137(58.4)$ & $234(100.0)$ \\
Have many birds died at once & $87(37.2)$ & $147(62.8)$ & $234(100.0)$ \\
Report to Vet. authority & $122(52.1)$ & $112(47.9)$ & $234(100.0)$ \\
Wild birds fly into farms & $158(67.5)$ & $76(32.5)$ & $234(100.0)$ \\
Visit to other farms & $155(66.2)$ & $79(33.8)$ & $234(100.0)$ \\
Other farmers' visit & $167(71.4)$ & $67(28.6)$ & $234(100.0)$ \\
Chicken sellers' visit &
\end{tabular}

$n$ : respondents awareness, \%: percentage, multiple response.

prevention measures showed 31.9\%; 59.1\% wash hands with antiseptics after touching birds (Table 4).

An $88.4 \%$ respondents believe public health information and communication awareness were helpful in controlling bird flu, 35.3\% of respondents indicated staying at home to avoid public places; $21.6 \%$ and $37.9 \%$ respondents were aware that wearing face mask and wearing hand gloves while handling sick birds could prevent bird flu transmission while $47.8 \%$ are aware that disinfection of equipments and contact surfaces could prevent bird flu as shown in Table 5.

\section{Discussion}

In this study, demographically, the number of males was greater than females who participated. This could be partly because (1) there are more males owning poultry farms than female in the study area, (2) intrinsically because of poultry farming being modernized with the improved breed stocked, a modernized management system, and highly capital intensive to which men are more likely to venture than women [6], and (3) modern poultry farming is more profitable than village chicken rearing by women. And men would choose modern poultry farming as an occupation rather than the traditional chicken rearing.

Most respondents are in the age groups of 21-40 years and 41-60 years, which when linked to most farms being located at home $(69.4 \%)$ makes this finding of public health significance. And more, $66.9 \%$ of respondents are married. Thus population of high socioeconomic importance is involved in poultry farming and sales, which could be a risk factor for bird flu in humans, this findings is corroborated by earlier work [7]. This finding implied that avian influenza is associated with a very high socioeconomic burden.

Participants' awareness of bird flu (Table 1) is higher than the study carried out in Lagelu, Oyo state, Nigeria (92.9\%), 2008 [8], with the electronic media being the source from which most farmers heard about bird flu (Table 1). This awareness level reflects in the educational status in which $72.0 \%$ respondents had attended secondary and tertiary schools. In a resource limited country like Nigeria, where electrical power is individually generated by a few that could own power generator, information dissemination would be hampered as only few farmers may access the information timely (outbreak and control measure news). Respondents also utilized radio as an important information source. Other sources were poorly utilized in knowing about bird flu. Extremely few respondents attended seminars on bird flu or there were just few seminars at the time of epidemic and subsequently. The findings suggested that mass communication with electronic and radio media would be the most effective media of information dissemination to the farmers and the populace.

Respondents' knowledge of bird flu transmission among birds and from bird to man is moderate (Table 2). Abysmally low understanding of transmission routes from man to bird, pig to bird, and vehicles and slaughter surfaces to birds and human was an important finding which suggested a knowledge gap by the respondents. Findings as such give an impression that farmers in this investigation have low knowledge of bird flu with increased possibility of ease of pathogen spread in farms which agreed with the study [9].

Respondents' knowledge of transmission from infected birds to man is higher than transmission from infected man (Table 3), which suggests increased awareness; this finding is higher than the study in turkey [10]. Infected birds is at the center of reported human cases that have resulted in mortality; rare cases of human to human transmission though have been reported $[9,11]$ but not in Benin City (Nigeria) the study area (personal communication). Awareness of the transmission of bird flu through contact with infected chickens, by touching infected chicken, is high; as well $67.9 \%$ respondents are aware of the zoonotic nature of the disease. Many respondents had experienced high mortality but only $37.2 \%$ reported such mortality to the veterinarian. Importantly, it implied poor level of awareness on the significance of disease reporting. This is supported by earlier finding of more respondents that got bird flu information from colleagues than from veterinarian (Table 1).

The LPS, an important stakeholder in poultry trade, practiced non consultation of the veterinarian for treatment of morbidity and mortality of poultry in the live animal markets, which is an important finding. This constituted a great risk to public health safety and contributed immensely perhaps to under diagnosis and reporting of avian influenza in Nigeria. The finding of increased interfarm visitation by respondents also showed poor understanding of the epidemiology of the disease, particularly the role of human, poultry, and poultry by-products movements and trade in pathogen spread and persistence in farms (Figures 2 and 3). This could suggest low awareness of biosecurity measures, increased risk of pathogen spread among farms, and a less organized poultry farming and trade. There is a moderate level of awareness of transmission through touching infected chicken (Table 3). This reflected the low usage of coverall, hand gloves, and face 
TABLE 4: Public health preventive measures that prevent zoonotic transmission of bird flu.

\begin{tabular}{|c|c|c|c|}
\hline \multirow{2}{*}{ Variable } & \multicolumn{3}{|c|}{ Frequency (\%), $n=232$} \\
\hline & Yes & No & Total \\
\hline \multicolumn{4}{|l|}{ Hand washing with antiseptic } \\
\hline Before entering pen & $104(44.8)$ & $128(55.2)$ & $232(100.0)$ \\
\hline Coming out of pen & $132(56.9)$ & $100(43.1)$ & $232(100.0)$ \\
\hline \multicolumn{4}{|l|}{ Disinfection of clothing } \\
\hline On entering pen & $62(26.7)$ & $170(73.3)$ & $232(100.0)$ \\
\hline On leaving farm & $82(35.3)$ & $150(64.7)$ & $232(100.0)$ \\
\hline Hand washing with antiseptic after touching birds & $137(59.1)$ & $95(40.9)$ & $232(100.0)$ \\
\hline Covering of mouth on coughing/sneezing & $200(86.2)$ & $32(13.8)$ & $232(100.0)$ \\
\hline Use of face mask while in the pen & $55(23.7)$ & $177(76.3)$ & $232(100.0)$ \\
\hline Can bird flu be prevented & $201(86.6)$ & $31(13.4)$ & $232(100.0)$ \\
\hline Vaccination of birds & $187(80.6)$ & $45(19.4)$ & $232(100.0)$ \\
\hline Vaccination of humans & $109(47.0)$ & $123(53.0)$ & $232(100.0)$ \\
\hline Training of workers on prevention & $74(31.9)$ & $158(68.1)$ & $232(100.0)$ \\
\hline
\end{tabular}

Multiple response, $n$ : number of respondents, \%: percentage.

TABLE 5: Control measures involving pharmaceutical and nonpharmaceutical methods.

\begin{tabular}{|c|c|c|c|}
\hline \multirow{2}{*}{ Variable } & \multicolumn{3}{|c|}{ Frequency (\%), $n=232$} \\
\hline & Yes & No & Total \\
\hline Use of antiviral drugs & $107(46.1)$ & $125(53.9)$ & $232(100.0)$ \\
\hline Use of unorthodox drugs & $68(29.3)$ & $164(70.7)$ & $232(100.0)$ \\
\hline $\begin{array}{l}\text { Public health information } \\
\text { and communication } \\
\text { awareness }\end{array}$ & $205(88.4)$ & 27 (11.6) & $232(100.0)$ \\
\hline Isolation of sick person & $137(59.1)$ & $95(40.9)$ & $232(100.0)$ \\
\hline $\begin{array}{l}\text { Staying at home to avoid } \\
\text { public places }\end{array}$ & $82(35.3)$ & $150(64.7)$ & $232(100.0)$ \\
\hline $\begin{array}{l}\text { Wearing protective clothing } \\
\text { in public places }\end{array}$ & $96(41.4)$ & $136(58.6)$ & $232(100.0)$ \\
\hline $\begin{array}{l}\text { Wearing face mask while } \\
\text { handling sick birds }\end{array}$ & $50(21.6)$ & $182(78.4)$ & $232(100.0)$ \\
\hline $\begin{array}{l}\text { Wearing hand gloves while } \\
\text { handling sick birds }\end{array}$ & $88(37.9)$ & $144(62.1)$ & $232(100.0)$ \\
\hline $\begin{array}{l}\text { Disinfection of equipments } \\
\text { and contact surfaces }\end{array}$ & $111(47.8)$ & $121(52.2)$ & $232(100.0)$ \\
\hline
\end{tabular}

$n$ : number of respondents, \%: percentage.

masks in the farms and markets as observed from the study (Figure 1), which agreed with the findings in turkey [12].

Awareness on practices (Table 4) that prevent zoonotic transmission and contagious spread among humans is low to moderate. The reasons are the following: (a) since the 20062008 epidemic avian influenza in poultry farms recorded no reported human cases, it could have caused farmers to quickly relax the practice of these measures; (b) due to few reported bird flu cases in farms, as such awareness of these measures perhaps must have been forgotten because usage might have stopped shortly after the epidemic recession; (c)

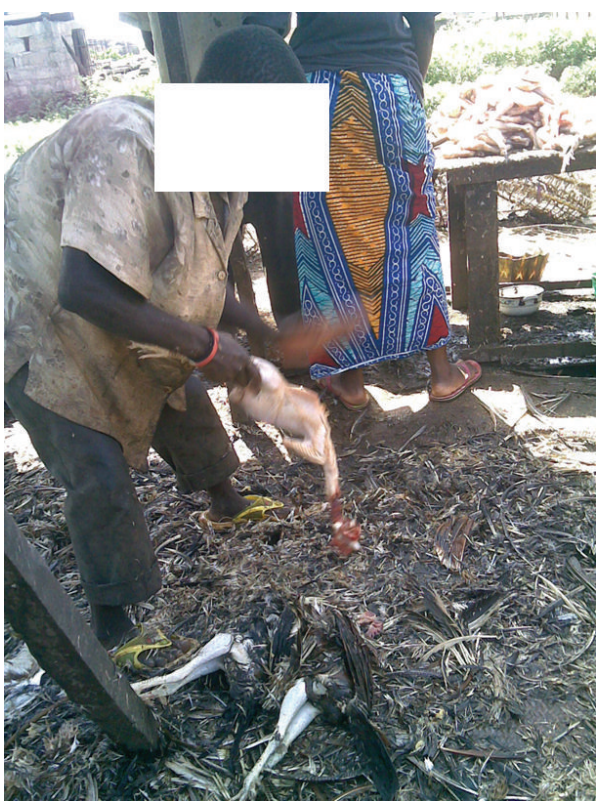

FIGURE 1: Worker dressing live chicken after slaughtering without personnel protective equipments (PPE), unhygienic processing that increases risk of viral transmission at the live poultry market.

human disease is rare, so a case definition for identification has not been established.

More respondents $86.6 \%$ of the respondents believed bird flu is preventable (Table 4 ) is higher than the $78.6 \%$ findings of an earlier study in Oyo, Nigeria [8]; this could perhaps be due to the practice of vaccination of birds against diseases like Newcastle disease, fowl typhoid, and infectious bursal disease that had resulted in the control of those diseases in farms. Disinfection of clothing in farms, hand washing with antiseptics before entering pens, and face mask use 


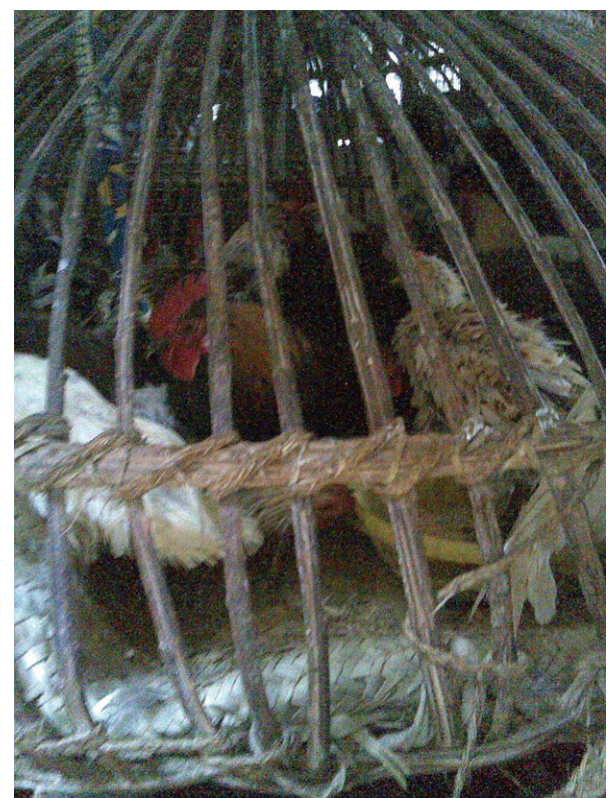

FIGURE 2: Cone shaped basket containing duck, chicken, and guinea fowl at the live poultry market.

(Table 4) as found indicated poor awareness which could imply low hygienic practices and poor understanding of disease dynamics in farms. These observations coupled with the increased interfarm visitation would mean that in the study area, increased movements and contacts among human and farms would greatly enhance bird flu transmission and ensure epidemics. High response to hand washing with antiseptics on leaving pens showed good awareness and invariably limiting the pathogen spread. The behavior could mean washing with clean water and bathing at the close of work only, especially in the commercial farms as witnessed by this author. Higher response to vaccination of birds with avian influenza vaccine indicated increased awareness and possibly acceptance of vaccination in farms; it could also mean ongoing vaccination of birds in the study area.

Public health information and communication awareness though helpful in educating the public on the disease, participants showed low usage of such information in this current study (Table 5). It could mean that they are poorly understood which corroborates findings elsewhere $[8,12]$. Respondents' awareness of antiviral and unorthodox drugs use is low, suggesting that human bird flu is unknown to the respondents. This perhaps would best explain the poor awareness of the nonpharmaceutical measures such as isolation of sick persons, staying at home to avoid public places, wearing face masks and hand gloves when handling sick birds. Wearing face masks and hand gloves responses could be as a result of non provision to the farm workers and poor acceptance as witnessed in farms by the author. These findings as corroborated by [9] implied increased and rapid possible zoonotic and epidemic transmission should there be an incidence of the HPAI (H5N1) V in this investigated area. In case of increased viral fitness for zoonotic transmission, large population could be quickly affected with a resultant

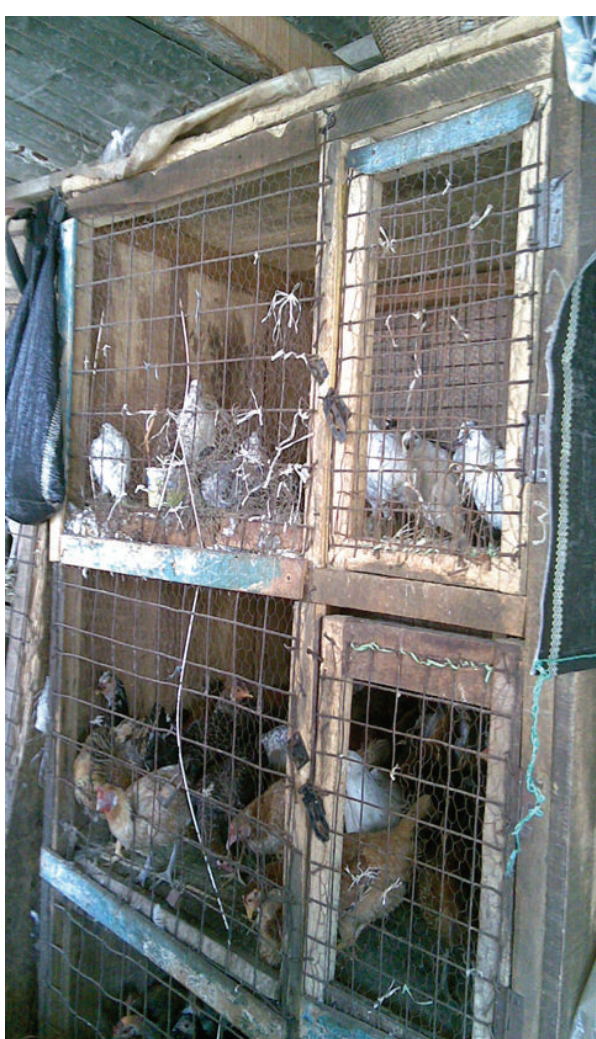

FIGURE 3: Wooden cage containing live pigeon and chicken in a multianimal live poultry market transported from the northern states, Nigeria, to Benin City (southern Nigeria).

increased mortality due to lack of disease identification, inadequate diagnostic capacity, lack of vaccine and non to existent but poorly equipped health care facility $[9,13,14]$.

Limitations. Due to self reporting, the data could not be validated independently. Refusal of some farmers to participate in the study is a potential bias. Increase in the participants on the tertiary education category did not give a true representation which could influence information education communication program.

\section{Conclusion}

There is an increased need to improve the awareness of these occupational groups on this important disease towards behavioral and attitudinal change to ensure compliance on the preventive measures. This is so because new farms and farmers have emerged since the recession of avian influenza that are might be insufficiently aware of disease dynamics and prevention. Governmental incentives to cushion the effect of severe bird mortality in farms will greatly enhance behavioral practices to protect farmers and improve disease reporting. An important finding is the poor awareness of avian influenza in humans which reflects poor understanding of pharmaceutical and nonpharmaceutical measures that could control zoonotic spread. Intersectoral collaboration of the veterinary and medical disciplines are required for case 
identification through occupational relationship to medical management. The poultry farms and LAM remain important as foci for epidemiological surveillance.

This study will greatly contribute to the understanding of the disease epidemiology in Nigeria. It is helpful in designing appropriate planning towards mitigating socioeconomic consequences associated with avian influenza.

\section{Consent}

Informed consent of individual participant was gotten.

\section{Conflict of Interests}

The authors declare that they have no conflict of interests.

\section{Acknowledgments}

Researchers privately funded the study. The authors are sincerely grateful to Dr. Ugochuwkwu, management and staff of Dominion Veterinary Consult, Faith Animal Concept, Jappar Nigeria Ltd., animal doctor, Poultry Association of Nigeria, Benin City, Edo State, for their assistance in data collection. Management of NVRI, Vom, are appreciated for their cooperation.

\section{References}

[1] R. A. Ocholi, I. L. Oyetunde, P. Kumbish et al., "Epidemiology of an outbreak of highly pathogenic avian influenza caused by the virus subtype H5N1 in Nigeria in 2006," Vom Journal of Veterinary Science, vol. 3, no. 1, p. 12, 2006.

[2] W. Gao, A. C. Soloff, X. Lu et al., "Protection of mice and poultry from lethal $\mathrm{H} 5 \mathrm{~N} 1$ avian influenza virus through adenovirusbased immunization," Journal of Virology, vol. 80, no. 4, pp. 1959-1964, 2006.

[3] M. E. Quiñones-Mateu and E. J. Arts, "Virus fitness: concept, quantification, and application to HIV population dynamics," Current Topics in Microbiology and Immunology, vol. 299, pp. 83-140, 2006.

[4] S. U. Schnitzler and P. Schnitzler, "An update on swine-origin influenza virus A/H1N1: a review," Virus Genes, vol. 39, no. 3, pp. 279-292, 2009.

[5] Nigerian Bureau of Statistics (NBS), "Federal Republic of Nigeria 2006 population census. Official Gazatte (FGP 71/52007/2, 500(OL24)," 2011, http://www.nigerianstat.gov.ng/.

[6] M. M. Kazeem, Assessment of the knowledge, attitude and practice of control measures to avert avian influenza (bird flu) among poultry farmers in Benin City, Edo State, Nigeria [MPH thesis], 2011.

[7] M. E. Thomas, A. Bouma, H. M. Ekker, A. J. M. Fonken, J. A. Stegeman, and M. Nielen, "Risk factors for the introduction of high pathogenicity Avian Influenza virus into poultry farms during the epidemic in the Netherlands in 2003," Preventive Veterinary Medicine, vol. 69, no. 1-2, pp. 1-11, 2005.

[8] A. A. Fatiregun and M. M. Saani, "Knowledge, attitudes and compliance of poultry workers with preventive measures for avian influenza in Lagelu, Oyo State, Nigeria," Journal of Infection in Developing Countries, vol. 2, no. 2, pp. 130-134, 2008.
[9] J. Beigel, J. Bion, J. D. Chiche, Z. Gao, and F. Hayden, "WHO Clinical management of infection with avian influenza A, (H5N1) virus," Updated advice, 2007.

[10] B. S. Kuckkaya and T. Erbaydar, "Behaviors and experiences of poultry owners in Dogubayazit whose poultry were culled during the avian influenza epidemic," European Journal of Public Health, vol. 22, no. 2, pp. 174-177, 2012.

[11] A. Kandeel, S. Manoncourt, E. A. el Kareem et al., "Zoonotic transmission of avian influenza virus (H5N1), Egypt, 20062009," Emerging Infectious Diseases, vol. 16, no. 7, pp. 1101-1107, 2010.

[12] J. T. Lau, J. H. Kim, H. Y. Tsui, and S. Griffiths, "Perception related bird-to human avian influenza, Influenza vaccination and use of face mask," Infection, vol. 36, no. 5, pp. 434-443, 2008.

[13] M. M. Kazeem and M. O. Kazeem, "How prepared are we for the pandemic influenza in Nigeria," in Proceedings of the Nigerian Veterinary Medical Association Congress, pp. 69-72, 2010.

[14] WHO, "Vaccine research and development: current status," 2005, http://www.who.int/csr/disease/avian_influenza/. 


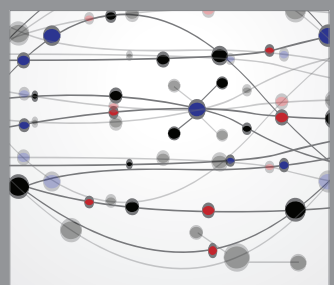

The Scientific World Journal
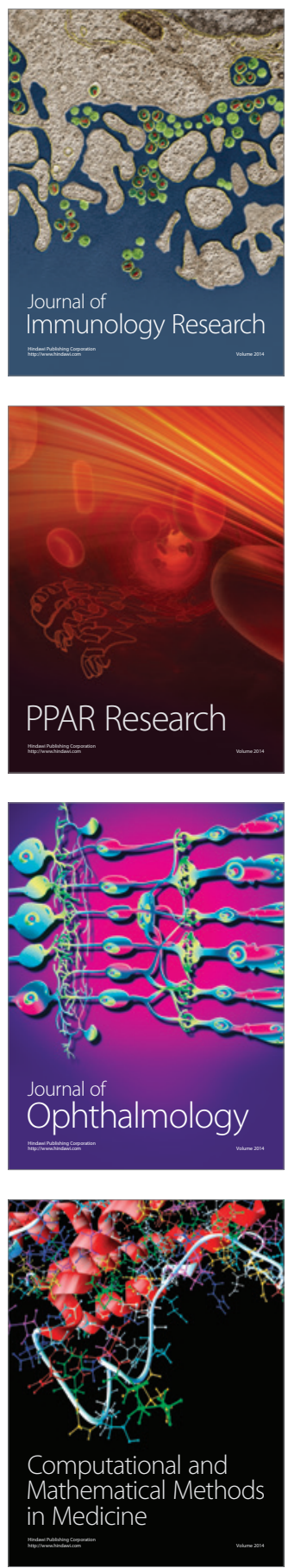

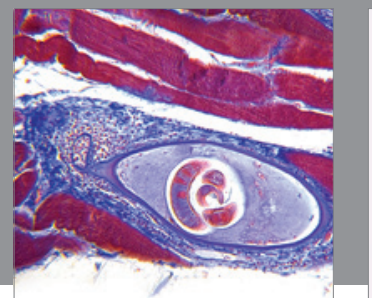

Gastroenterology

Research and Practice
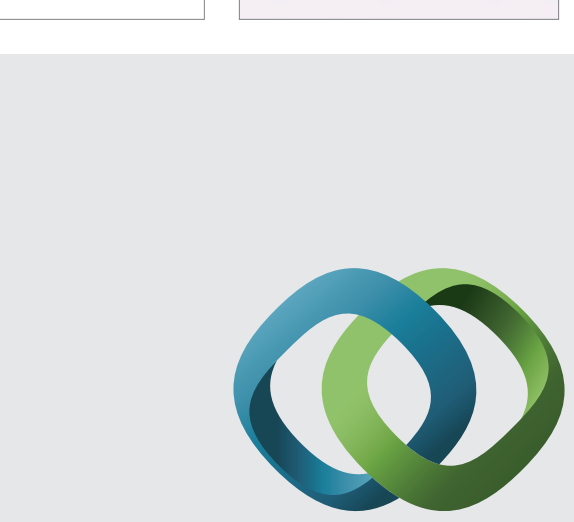

\section{Hindawi}

Submit your manuscripts at

http://www.hindawi.com
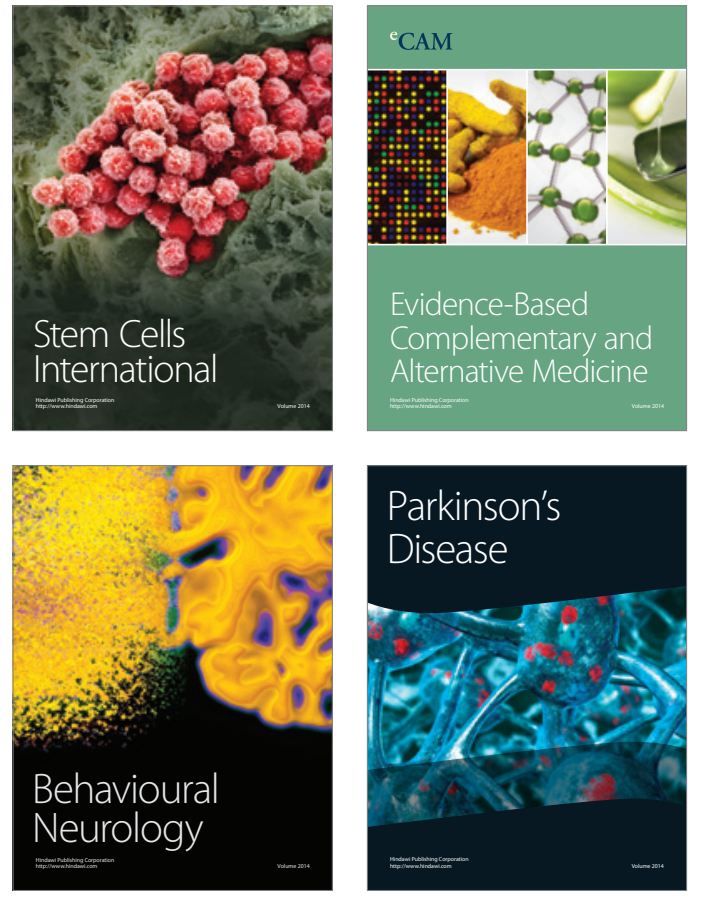
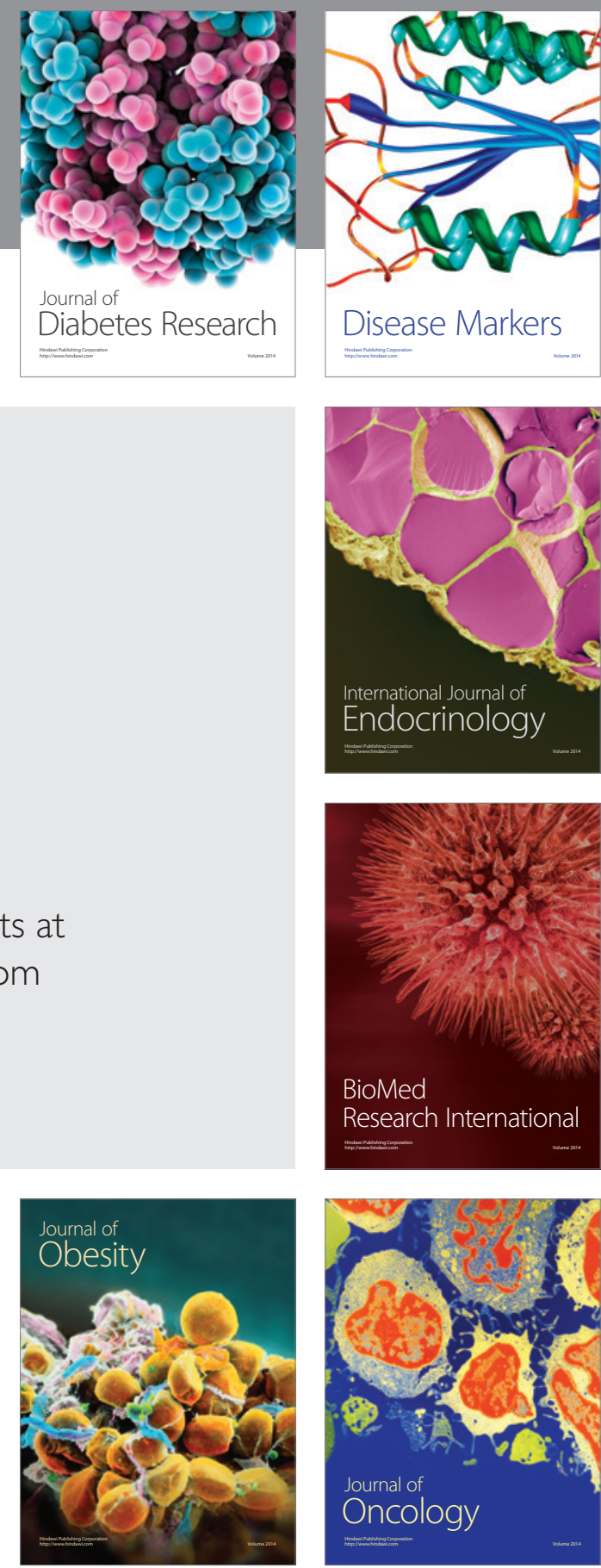

Disease Markers
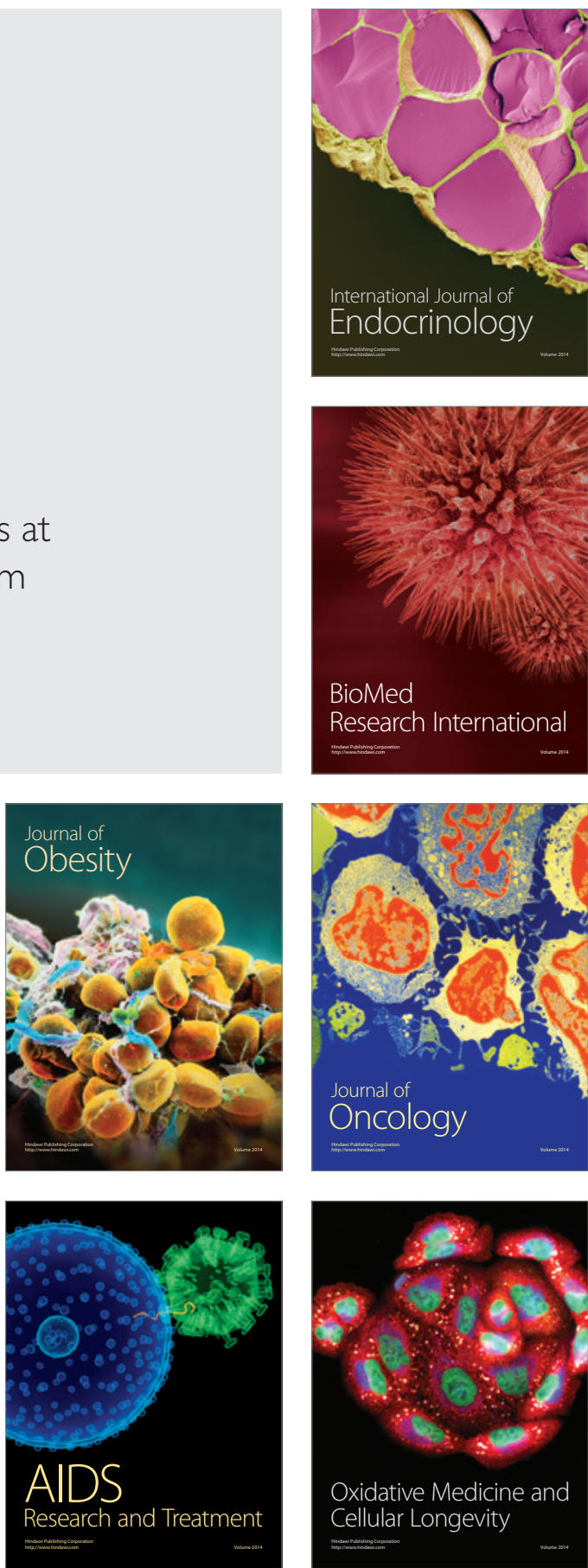